\title{
Bilateral Insular Lesions Related to Malignant Hypertension
}

\author{
Shunsuke Kobayashi ${ }^{1}$, Akihiko Hoshi ${ }^{1}$, Kenichi Tanaka ${ }^{2}$ and Yoshikazu Ugawa ${ }^{1}$
}

Key words: hypertensive encephalopathy, malignant hypertension, posterior reversible encephalopathy syndrome, magnetic resonance imaging, insular cortex

(Intern Med 51: 1805-1806, 2012)

(DOI: 10.2169/internalmedicine.51.6692)
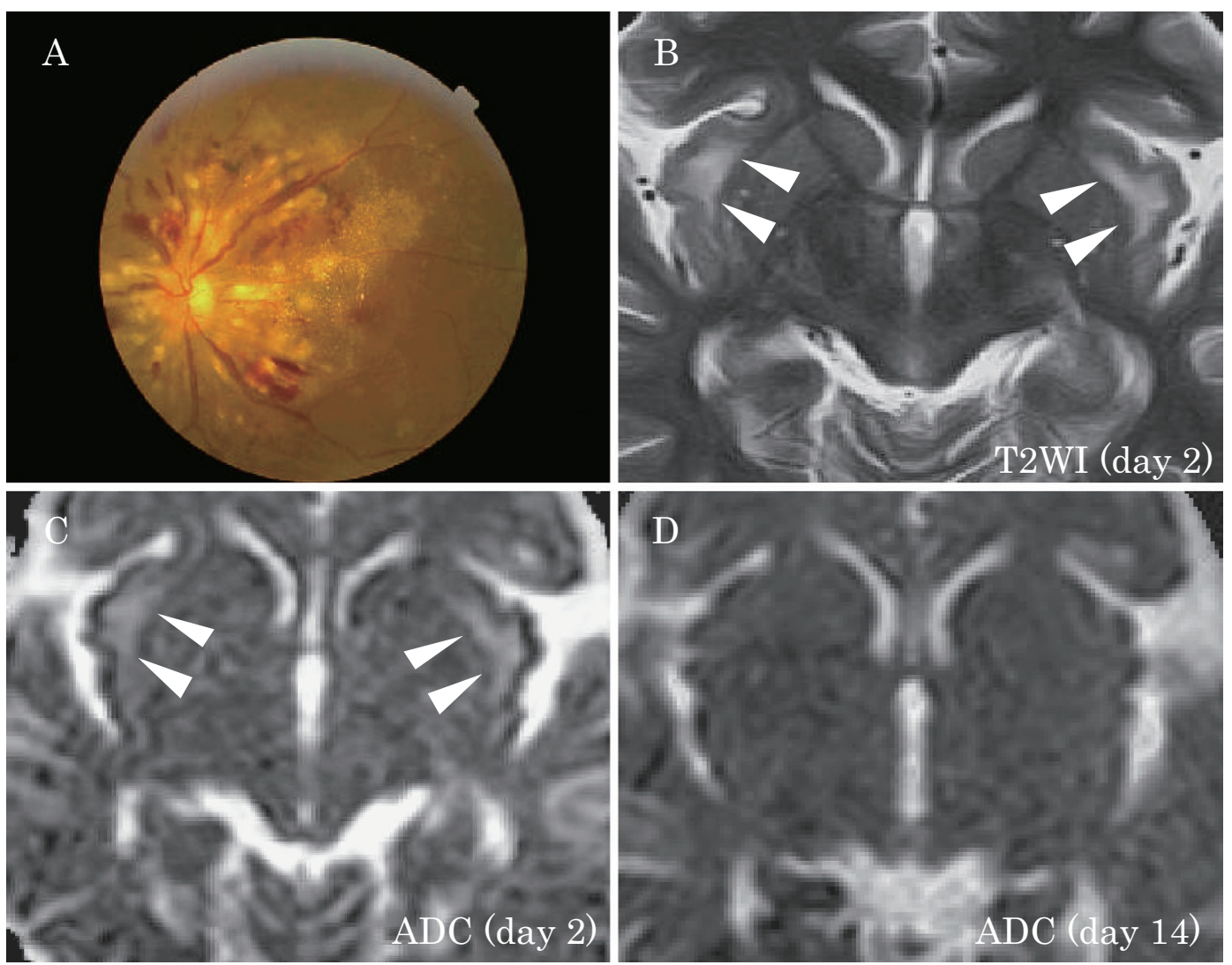

Picture.

A 25-year-old man with untreated hypertension gradually developed blurred vision and nausea. At admission, his blood pressure was $216 / 164 \mathrm{mmHg}$. A diagnosis of malignant hypertension was made and his visual symptom was attributed to hypertensive retinopathy (Picture A). Neurological examinations were not remarkable except for generally brisk deep tendon reflexes. Initial brain MRI showed abnormal signals in the bilateral subinsular white matter on T2weighted (Picture B) and diffusion-weighted sequences. The lesions showed elevated apparent diffusion coefficient (ADC) (Picture C). Hypertension was well controlled by nifedipine and olmesartan medoxomil and the abnormal subinsular signals were almost completely resolved (Picture D).

Hypertensive emergency typically involves posterior cerebral white matter, hence the term posterior reversible encephalopathy syndrome (PRES) (1). Although the subinsular lesions of our patient are atypical, reversible vasogenic

${ }^{1}$ Department of Neurology, Fukushima Medical University, Japan and ${ }^{2}$ Department of Nephrology and Hypertension, Fukushima Medical University, Japan

Received for publication March 6, 2012; Accepted for publication March 26, 2012

Correspondence to Dr. Shunsuke Kobayashi, skoba-tky@umin.net 
edema, demonstrated by transiently increased ADC signal, is a hallmark of PRES, which is presumably caused by breakdown of cerebral autoregulation (2).

The authors state that they have no Conflict of Interest (COI).

\section{Acknowledgement}

We would like to thank Dr. Ichiro Maruko for ophthalmologi- cal examination.

\section{References}

1. Vaughan CJ, Delanty N. Hypertensive emergencies. Lancet 356: 411-417, 2000.

2. Bartynski W. Posterior reversible encephalopathy syndrome, part 2: controversies surrounding pathophysiology of vasogenic edema. Am J Neuroradiol 29: 1043-1049, 2008.

\footnotetext{
(C) 2012 The Japanese Society of Internal Medicine http://www.naika.or.jp/imindex.html
} 